is not insisted upon as much as should be the case. There are practical difficulties in the way in the case of hospital patients, who are usually supplied with large bi-convex lenses, on account of their extreme thickness, and also, to a slight extent, on account of the increased expense involved in making the glasses out of a tint. In the more modern and expensive "luxe" type of cataract lens the matter is easier. Crookes' A glass or the lightest shade of London Smoke or Fieuzal are the most suitable tints to employ, and personally I much prefer the Crookes' A, as being the less disfiguring and the most suitable for the purpose. I feel strongly that all aphakic patients should have some protection outdoors, except on dark and cloudy days, and if the lenses are made out of Crookes' A, the same glasses will do for indoors as well as outdoors, without materially interfering with the patient's comfort. Reading lenses may be similarly constructed, and should indeed be so made if the patient is wearing lenses made out of Crookes' A glass at all other times.

In active inflammatory disease of the retina and choroid, I much prefer, and always order, Peacock Blue. By it all ultra-violet and infra-red radiations are entirely shut off, and a very large proportion of the luminous rays as well. It has a peculiarly soothing effect on the patient, and forms a most valuable kind of treatment. There is, to my mind, no other tint comparable with it.

\title{
A NOTE ON THE LATERAL OCULAR MUSCLE BALANCE IN SCHOOL CHILDREN, WITH SPECIAL REFERENCE TO SQUINT IN MYOPIA*
}

BY

Ernest Thomson, M.D.

STIRLING

Much study has been given to heterophoria and a great deal has been written about it, yet it is doubtful whether statistics of tests of the muscle balance in any considerable number of children have been published. For that reason alone the present figures, although only covering some 500 cases, may be of interest. Yet statistics as such, and without a direct purpose, are not the primary interest of this article.

In the July, 1919, number of this journal the writer published

*This article was written several years ago. It is now published in order to supplement the writer's opening paper at the Oxford Congress, 1924, on the "Treatment of Convergent Concomitant Strabismus." It is much to be regretted that an error crept into the MS. of Table II, as sent to the printer (Trans. Ophthal. Soc. of the U.K., 1924, p. 241) where the figures for the 4th group are wrongly given. The correct figures for the 24 Emmetropic cases are: Orthophoria, 1; exophoria, 5; esophoria, 18; the ratio exophoria to esophoria being 1 to 3.6 . 
an article entitled: "Some Statistics of Myopia in School Children," in which it was stated that in the 790 cases of myopia and myopic astigmatism then under analysis "convergent squint was not only not less frequent but was actually more frequent than divergent." It was also said, "I am free to admit that my records of exophoria are not trustworthy, and, therefore, they have not been stated."

Subsequent reflection indicated that it was advisable to endeavour to ascertain the condition of muscle balance in a series of nonsquinting children coming up for "visual" treatment in the area of the country of Lanark Education Authority. Originally 1,000 was the number aimed at, but circumstances necessitated the reduction of this to 500. Actually 497 cases were recorded. Of the 497 cases eleven were rejected as not satisfactory. There remains a total of 486 upon which the statistics in the accompanying table are based.

- It is difficult during the pressure of school refraction work to devote much time to scientific investigation, and so it was reluctantly decided that only the lateral balance could be tested, and that qualitatively only. The vertical component was not investigated.

The question may be asked whether the statements of children as to the position of the Maddox red line can be considered as reliable. The answer to that is that the writer found the average school child to be remarkably sharp and positive as to the right or left position of the line relative to the light, and more was not asked. Any child who hesitated was either omitted from the statistics altogether or was admitted only after a second trial. Had it not been for the rejection of the duller children the numbers recorded would have been considerably larger.

There were two circumstances of test. In the first group the child was attending for the first time and was tested for muscle balance after taking the visual acuity and before the instillation of atropin.* In the second group the child attended with the spectacles previously prescribed and the Maddox test was carried out with the spectacles on. The cases do not overlap; those in the first category are not the same children as those in the second. The statistics, therefore, refer actually to individuals. In every case the refraction was worked by retinoscopy under atropin. The condition of refraction, having been objectively ascertained can be fairly well vouched for; that of the

\footnotetext{
* In this connection I may be allowed to point out that the refraction was worked under atropin in all the cases dealt with in both of my articles and that the classification was made thereafter. In his Opening Paper at the Oxford Congress, 1924, when referring to my previous communication, Dr. Landolt said, "We need only recollect that myopia in children is most often due to spasm of accommodation." With this statement I, personally, am in complete disagreement, but it is possible that the author, speaking in a foreign language, did not intend the statement to be quite so definite.
} 
muscle balance, subjectively ascertained, must be allowed a margin of error, but the error is probably not great as between qualitative exophoria and esophoria.

It may be well to state exactly what questions were asked of the child. The Maddox rod having been placed before one eye (the better eye if any difference of acuity.) the child is asked : "Do you see a red line up and down?" "Yes." "Is the red line straight up and down?" "Yes." (If "No" then of course the rod is rotated till the line appears straight.) Then, touching the child first on the right and then on the left arm, "Tell me which side of the light the red line is on; put up the arm which shows which side." As a rule this is done so smartly as to leave no doubt, though, of course, a considerable number boggle over it and contradict themselves. Such children find no place in the statistics. Orthophoria was accepted when the child stated spontaneously that the line passed through the light. The leading question was not asked, "Is the line through the light?" except when an apparently intelligent individual seemed to hesitate in giving a reply to the "which side" question.

It is perhaps advisable to state that the source of light had to be larger than one would wish to employ. It was necessary to make sure that both images were unmistakably seen and that without too much delay.

The ages of the children examined (taking the whole number, 497) were as follow :

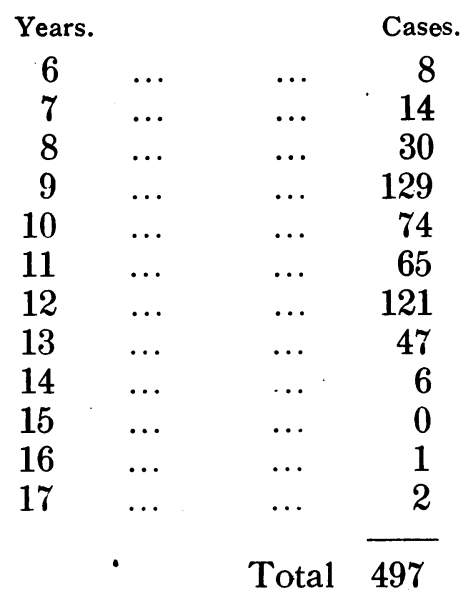

Passing now to the consideration of the actual figures and their bearing on the question of squint in myopia, one finds that, as always, "anisometropia" is the stumbling block in statistics dealing with binocular vision. In reports to eye hospitals, 
education authorities, etc., one finds the reporter in the uncomfortable position of being expected to state the number of different refraction cases when, in reality, some patients represent two different types of refraction. A satisfactory definition of anisometropia is still to seek. Jackson believes that anisometropia will always have, in practical use, a somewhat indefinite significance, and that at best it is used to designate a condition with variable limits (Am. Enc. of Ophthal.). For example, one can hardly deny that if one eye presents myopia or myopic astigmatism and the other eye mixed astigmatism, there is anisometropia, yet the latter may differ from the former only to a slight degree.

The writer came to the conclusion that, for the purpose in view at any rate, the only method of dealing with this difficulty is to ascertain the numbers of exophorias, esophorias and orthophorias 9 occurring in all the possible combinations of binocular refraction, and then to classify these combinations into groups. As will be seen on reference to the table this has been done, the groups $\stackrel{\rho}{\mathcal{S}}$ numbering four, namely, the Hypermetropic Group, the Myopic $\vec{o}$ Group, the Anisometropic Group, and the Emmetropic Group 워 (both eyes emmetropic). This classification is far from perfect. For instance, where one eye is emmetropic, the other ametropic, the case has been considered binocularly as belonging to the group corresponding to the ametropic eye and not to the anisometropic group. Again mixed astigmatism has been regarded as belonging to the myopic group since the myopic element is usually the larger and because the tendency is towards myopic astigmatism in the long run.

It is possible that the table may be interesting (though the numbers are too small to be of much use from a general standpoint) from other aspects, but the purpose of this article is the single one of showing the relation of exophoria and esophoria respectively to myopic refraction and of comparing the result with the relation of divergent and convergent squint to myopic refraction.

Taking from the table, column 3 , the myopic type as a complete group of 159 cases ( 69 without and 90 with correction) we find that exophoria is to esophoria approximately as 34 per cent. is to 62 per cent.. (orthophoria making up the 100). If it be objected that in a myopic group one eye at least must be myopic we may leave out MX and MX, and MX and E. That leaves 117 cases in the myopic group, and, of these, exophoria is to esophoria approximately as 39 per cent. is to 56.5 per cent. (orthorphoria making up the 100).

Referring now to the article on myopia in school children previously mentioned, it will be found that out of 790 cases of myopia and myopic astigmatism in one or both eyes there were 29 divergent squints and 45 convergent squints, the percentages 
being 3.67 to 5.69 . Some of these squints were doubtful. If we omit these (namely 2 divergent and 7 convergent) there are left 27 divergent and 38 convergent squints, the percentage now becoming 3.41 to 4.81 .

It is obvious that the ratios between exophoria and esophoria, as recorded in the present article, are similar to the ratios between divergent and convergent squints in myopia as tabulated in the previous article.

To make the demonstration, the ratios can be set out as follows :

In 159 cases of the so-called myopic type (see Table) with and without correction, exophoria is to esophoria as $\ldots \quad \ldots \quad \ldots \quad \ldots \quad \ldots$

Or, omitting from the above, binocular mixed astigmatism and emmetropia with mixed astigmatism, there are 117 cases with and without correction in which exophoria is to esophoria as $\quad \ldots \quad \ldots \quad \ldots \quad \ldots \quad \ldots$

In 790 cases of myopia and myopic astigmatism in one or both eyes (Brit. Jl. of Ophthal., July, 1919 ) divergent squint is to convergent squint as 29 to 45 , that is $\ldots \ldots \ldots$

Or, omitting doubtfuls from the above, as 27 to

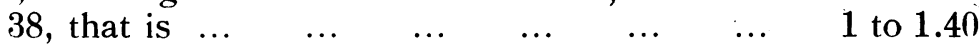

While the writer anticipates criticism of his statistics on the grounds (1) that they are too small; (2) that no account was taken of deviations other than lateral; and (3) that children are not supposed to be satisfactory patients where subjective examination of this kind is concerned, he feels nevertheless that the correspondence between the two sets of figures, the one showing the ratio between exophoria and esophoria in the myopic type-group of nonsquinting children and the other the ratio between actual divergent and convergent squints in myopic children, is close enough to show that not only was convergent squint more common than divergent in 790 myopic children previously examined, but that (although the group is smaller) in a group of myopic children belonging to the same area who did not squint, the tendency to convergence was greater than the tendency to divergence by approximately the same amount.

Although only a portion of the accompanying table has been utilized in the thesis here maintained it has been thought proper to publish the complete figures. These may possibly prove of interest. Two points seem to stand out. Firstly, the great preponderance of esophoria in children, in all types of refraction, though especially in the hypermetropic and anisometropic types. Secondly, there is no particular evidence that one group of children wearing correction differs materially as regards the quality 
of the lateral balance from another group of children not wearing correction. The writer hopes to be able to ascertain whether in the same children tested with and without correction there is any manifest change in the muscle balance.

'TABLE showing the number of cases belonging to each Type-group of Binocular Refraction (total 486) and the percentage Relation between Orthophoria, Exophoria and Esophoria.

\begin{tabular}{|c|c|c|c|c|c|c|c|c|c|}
\hline \multirow{3}{*}{ HYPERMETROPIC TYPE } & \multicolumn{3}{|c|}{ Without Correction 290} & \multicolumn{3}{|c|}{ With Correction 196} & \multicolumn{3}{|c|}{$\begin{array}{c}\text { Total } \\
\text { With and without } \\
\text { Correction } 486\end{array}$} \\
\hline & Ortho & Exo & Eso & Ortho & Exo & Eso & Ortho & Exo & Eso \\
\hline & \multicolumn{2}{|l|}{1} & \multirow{6}{*}{$\begin{array}{r}30 \\
28 \\
78 \\
0 \\
4\end{array}$} & \multirow{6}{*}{3} & & & & \multirow[b]{2}{*}{22} & \multirow[b]{2}{*}{56} \\
\hline $\mathrm{H}$ and $\mathrm{H}$ & 0 & 15 & & & 7 & & 3 & & \\
\hline $\mathrm{H}$, HA & 1 & 4 & & & 2 & 11 & 2 & 6 & 39 \\
\hline $\mathrm{HA}$, , $\mathrm{HA}$ & 1 & 12 & & & 4 & 39 & 2 & 16 & 117 \\
\hline $\mathrm{H}, \quad \mathrm{E}$ & 0 & 2 & & & 0 & 0 & 0 & 2 & 0 \\
\hline $\mathrm{HA}, . \quad \mathrm{E}$ & 0 & 0 & & & 0 & 0 & 0 & 0 & 4 \\
\hline \multirow[b]{2}{*}{ Group Percentage } & 2 & 33 & 140 & 5 & 13 & 76 & 7 & 46 & 216 \\
\hline & 1.14 & 18.85 & 80.00 & 5.318 & 13.83 & 80.85 & 2.6 & 17.10 & 80.29 \\
\hline MYOPIC TYPE & & & \multirow[b]{2}{*}{4} & & \multirow[b]{2}{*}{8} & \multirow[b]{2}{*}{12} & \multirow[b]{2}{*}{2} & \multirow[b]{2}{*}{12} & \multirow[b]{2}{*}{16} \\
\hline$M$ and $M$ & 2 & 4 & & 0 & & & & & \\
\hline M " MA & 0 & 1 & 3 & 0 & 4 & 3 & 0 & 5 & 6 \\
\hline M ", MX & 0 & 0 & 3 & 0 & 0 & 0 & 0 & 0 & 3 \\
\hline $\mathbf{M} \quad$ E & 0 & 0 & 1 & 0 & 0 & 0 & 0 & 0 & 1 \\
\hline MA ., MA & 1 & 8 & 12 & 2 & 15 & 22 & 3 & 23 & 34 \\
\hline MA ,, MX & 0 & 3 & 2 & 0 & 1 & 0 & 0 & 4 & 2 \\
\hline $\mathrm{MA}, \ldots \mathrm{E}$ & 0 & 2 & 1 & 0 & 0 & 3 & 0 & 2 & 4 \\
\hline MX , MX & 1 & 2 & 18 & 0 & 6 & 12 & 1 & 8 & 30 \\
\hline \multirow[t]{2}{*}{$\mathbf{M X},, \quad \mathrm{E}$} & 0 & 0 & 1 & 0 & 0 & 2 & 0 & 0 & \\
\hline & 4 & 20 & 45 & 2 & 34 & 54 & 6 & 54 & 99 \\
\hline Group Percentage & 5.79 & 28.98 & 65.21 & $2 . \dot{2}$ & $37 . \dot{7}$ & 60 & 3.77 & 33.96 & 62.26 \\
\hline ANISOMETROPIC TYP & & & & & & & & & \\
\hline $\mathrm{H}$ and $\mathrm{M}$ & 0 & 0 & 1 & 0 & 0 & 0 & 0 & 0 & 1 \\
\hline $\mathrm{H} \quad$, MA & 0 & 0 & 2 & 0 & 0 & 0 & 0 & 0 & 2 \\
\hline $\mathrm{H}$, MX & 0 & 0 & 6 & 0 & 2 & 3 & 0 & 2 & 9 \\
\hline $\mathrm{HA}_{,}, \mathrm{M}$ & 0 & 0 & 0 & 0 & 0 & 0 & 0 & 0 & 0 \\
\hline $\mathrm{HA}$, MA & 0 & 0 & 1 & 0 & 0 & 1 & 0 & 0 & 2 \\
\hline $\mathrm{HA},, \quad \mathrm{MX}$ & 1 & 2 & 9 & 0 & 0 & 6 & 1 & 2 & 15 \\
\hline & 1 & 2 & 19 & 0 & 2 & 10 & 1 & 4 & 29 \\
\hline Group Percentage .. & 4.54 & 9.09 & 86.36 & 000 & 16.66 & 83.33 & 2.94 & 11.76 & 85.29 \\
\hline EMMETROPIC TYPE.. & 1 & 5 & 18 & & & & & & \\
\hline Group Percentage .. & 4.16 & 20.83 & 75.00 & & & & & & \\
\hline
\end{tabular}

